Revista Thema

V.18 Especial 2020

p. $92-110$

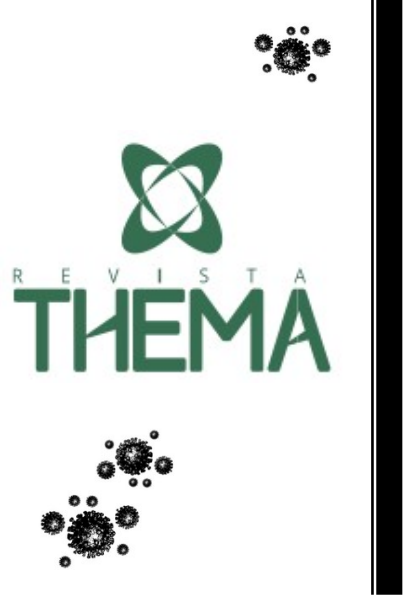

DOI: http://dx.doi.org/10.15536/thema.V18.Especial.2020.92-110.1827

ISSN: 2177-2894 (online)

\title{
Subcidadania, raça e isolamento social nas periferias brasileiras: reflexões em tempos de COVID-19
}

\author{
Subcitizenship, race and social isolation in Brazilian \\ peripheries: reflections in times of COVID-19 \\ Ronan da Silva Parreira Gaia ${ }^{1}$
}

\section{RESUMO}

O presente artigo busca problematizar questões acerca das condições para seguir as recomendações de isolamento social sugeridas pela Organização Mundial da Saúde no contexto das periferias brasileiras durante o período da pandemia causada pela COVID-19. De maneira a contextualizar a realidade nas periferias, que buscam enfrentar e/ou podem ser vítimas em massa dessa doença, este artigo dialoga com os dados, a partir de análise crítica da literatura, relatos de experiência e notícias jornalísticas. Entendendo a importância de relacionar as questões de raça e classe do Brasil e de suas faces, sobretudo no atual quadro marcado pela ideologia bolsonarista, o estudo propõe colocações preocupadas principalmente com a população periférica e subcidadã, a qual também é majoritariamente negra. Com atenção especial a marginalidade social desses sujeitos, é ressaltada a importância de compreender as segregações sociorraciais de nosso país e de realizar pesquisas que contemplem esse quadro.

Palavras-chave: Raça; subcidadania; isolamento social; periferias.

\section{ABSTRACT}

This article seeks to problematize questions about the conditions to follow the recommendations of social isolation suggested by the World Health Organization in the context of the Brazilian peripheries during the period of the pandemic caused by COVID-19. In order to contextualize the reality in the peripheries, which seek to face and/or may be mass victims of this disease, this article dialogues with the data, based on a critical analysis of literature, experience reports and journalistic news. Understanding the importance of relating the issues of race and class in Brazil and its faces, especially in the current situation marked by the ideology of the current President, the study proposes positions mainly concerned with the peripheral and sub-citizen population, which is also mostly black. With special attention to the social marginality of these subjects, the importance of understanding the socio-racial segregations of our country and carrying out research that contemplates this situation.

Keywords: Race; subcitizenship; social isolation; peripheries.

\footnotetext{
${ }^{1}$ Universidade de São Paulo - USP, Ribeirão Preto/SP - Brasil. E-mail: ronangaia@yahoo.com.br
} 


\section{INTRODUÇÃO}

O ano de 2020 indubitavelmente será marcado pela pandemia causada pelo novo coronavírus. A COVID-19 atua no momento em escala global e tem afetado milhões de indivíduos, gerando consequências complexas em diversos âmbitos da sociedade que vão para além da saúde, como a economia, a educação e as desigualdades sociais. Diversas sociedades têm se mobilizado contra esse desconhecido inimigo em comum e no Brasil não é diferente, apesar de algumas insistências contrárias aos necessários movimentos de combate ao vírus.

De acordo com o cronograma elaborado pela Sanar Med, empresa que reúne médicos brasileiros, o primeiro caso confirmado da COVID-19 no país foi em 26 de fevereiro, desde então esse número vem crescendo. Em 11 de março, a Organização Mundial da Saúde (OMS) declara que a doença avançou ao nível de uma pandemia. Uma semana depois, em 17 de março, é confirmada a primeira morte no Brasil. Até a data de 27 de abril de 2020, o país possui 66.501 (sessenta e seis mil, quinhentos e um) casos confirmados e 4.543 (quatro mil, quinhentos e quarenta e três) óbitos causados pela doença².

O Brasil calculava, em 40 dias de contágio, um índice de 4,9\% de letalidade pelo vírus, total superior ao número de contágio do mesmo em outros países nesse mesmo período. (PLATERO; GOMES, 2020). Em publicação sobre o assunto, articulando as análises sociológicas possíveis aos dados conhecidos até então Platero e Gomes (2020) concluem que enquanto o indicador de letalidade diminui, o número de mortes aumenta, o que deve ser observado para costurar integralmente a discussão acerca dos resultados dessa pandemia no contexto brasileiro. Esses números e análises condizem com a situação periférica do país, ao passo que justamente as margens são as maiores vítimas na ocasião de crises como essa. É tanto por isso que esse quadro nos incita a uma inerente preocupação com a população periférica brasileira. Embora seja um problema recente, e não existem muitas pesquisas concluídas sobre o assunto, é possível observar que a letalidade, ou seja, o número de mortos relacionados ao número de contágio, em bairros periféricos é maior. Trata-se da periferia das margens, a marginalização do que já periférico. A título de exemplificação, podemos apontar para o caso do bairro da Brasilândia, na zona norte de São Paulo capital, onde dos 89 casos confirmados da doença, há 54 mortos; em contrapartida, o bairro do Morumbi, na zona sul da mesma cidade, conta com 297 pacientes confirmados e apenas 07 óbitos $^{3}$. (RODRIGUES; BORGES; FIGUEIREDO, 2020). Além disso, o que está diretamente associado às periferias brasileiras, não podemos descartar a problemática racial desses números, já que também está confirmado que a letalidade do vírus tem atingido em maior proporção à população negra, realidade vista tanto no Brasil como nos Estados Unidos. (SIMÕES, 2020).

\footnotetext{
2 SANAR MED. Linha do tempo do Coronavírus no Brasil. 2020. Disponível em: <https://www. sanarmed.com/linha-do-tempo-do-coronavirus-no-brasil>. Acesso em: 27 abr. 2020.

${ }^{3}$ Ambos os dados dizem respeito a data de 18 de abril de 2020.
} 
Diante deste infeliz contexto, ainda existe o impasse da dificuldade quase que tradicional em realizar análises científicas que dialoguem com as questões de classe, raça e suas respectivas desigualdades no Brasil (RAMOS, 1995), o que impacta negativamente os resultados de pesquisas. Talvez isso se explique porque o Brasil secundariza a questão das desigualdades ao passo que não consegue compreendêlas. (SOUZA, 2003). Ao que tange essa falta de perspectiva racial sobre classes no Brasil, esse texto se fundamenta frente aos impasses observados nas pesquisas brasileiras em torno do coronavírus na nossa sociedade. Nesses termos, e a fim de sanar essa problemática acadêmica, neste artigo buscamos trabalhar com o conceito de subcidadão de Jessé de Souza (2018b), entendendo que se trata de uma ideia já bem consolidada que colabora com a estruturação de um pensamento acerca das consequências sócio raciais do COVID-19 no Brasil.

Por outro lado, este estudo também bebe do empirismo social observado através do papel do autor como supervisor técnico do Programa Criança Feliz de Ribeirão Preto/SP. Trata-se apenas de algumas informações relativas às visitas para melhor sustentar esta discussão, interessada em trabalhar acerca das questões sociais nas periferias brasileiros a partir de uma pesquisa bibliográfica voltada, principalmente, a obra do sociólogo Jessé de Souza (2003; 2005; 2018a; 2018b). Embora não se trate dos dados primais ao texto em tela, esta colocação foi importante não somente pela maior sustentação ao que foi exposto, mas sobretudo devido às observações que incitaram a realização deste estudo. Ao acompanhar a equipe de Visitadores Sociais em visitas domiciliares, foi observado que em toda a cidade a maioria das 500 famílias periféricas acompanhadas pelo programa seguem suas rotinas normalmente, apesar da política de isolamento social. Acreditando que este não é um quadro restrito ao interior paulista, encontramos amparo na realização das reflexões que seguem nos parágrafos abaixo. Entendemos ainda que é preciso pensar maneiras que possibilitem a participação social no combate ao coronavírus nos mais distintos contextos encontrados nos núcleos de favelas. Portanto, a intenção deste artigo é refletir sobre as problemáticas do isolamento social recomendado pela OMS e pelo Ministério da Saúde (na gestão de Luiz Henrique Mandetta) e flexibilizado na gestão nas periferias do Brasil.

Nesse contexto, e tendo em vista a atuação profissional do autor do presente artigo, acreditamos que o trabalho do Programa Criança Feliz (PCF) ${ }^{4}$ é estratégico para traçar

\footnotetext{
${ }^{4}$ É oportuno destacar que o Programa Criança Feliz tem por objetivo “(...) promover o desenvolvimento humano a partir do apoio e do acompanhamento do desenvolvimento infantil integral na primeira infância; apoiar a gestante e a família na preparação para o nascimento e nos cuidados perinatais; colaborar no exercício da parentalidade, fortalecendo os vínculos e o papel das famílias para o desempenho da função de cuidado, proteção e educação de crianças na faixa etária de até seis anos de idade; mediar o acesso da gestante, das crianças na primeira infância e das suas famílias às políticas e serviços públicos de que necessitem; integrar, ampliar e fortalecer ações de políticas públicas voltadas para as gestantes, crianças na primeira infância e suas famílias. (BRASIL, 2017, p.9)" e trabalha através de visitas de visitadores sociais aos domicílios de seu público alvo e tem como meta atender 500 indivíduos beneficiários por mês e seu atendimento “ocorre por meio de mediação/intervenção, escuta ativa e qualificada durante as visitas e acompanhamentos (semanais, quinzenais e/ou mensais) dos
} 
análises empíricas sobre a realidade das favelas nesse momento ${ }^{5}$. Em atividade, no município de Ribeirão Preto desde 2017, o programa é operado pelo Instituto de Desenvolvimento Social e da Cidadania em parceria e coordenação do Departamento de Proteção Social Básica (DPSB) da Secretaria Municipal de Assistência Social (SEMAS) e complementa o PAIF dos Centros de Referência de Assistência Social CRAS. (GAIA; CANDIDO; BARBOSA JÚNIOR, 2019). O público alvo do PCF é justamente os sujeitos em vulnerabilidade social, crianças de zero a três anos de idade, gestantes beneficiárias do Bolsa Família e/ou cadastradas no Cadastro Único da Assistência Social - CadSUAS, crianças na primeira infância que recebem o Benefício de Prestação Continuada (BPC) e suas famílias. (Ibid., 2019). Por isso, o atendimento do programa se dá fortemente nas regiões de favelas, permitindo alcançar famílias que vivem a dificuldade de se adaptar ao isolamento social, cujos depoimentos em muito somaram para os resultados e reflexões do presente artigo e se adequam a rotina do que interpretamos, apoiados por Jessé Souza (2018b), como subcidadão.

\section{O SUBCIDADÃO BRASILEIRO}

O interesse no conceito de subcidadão do sociólogo Jessé Souza (2018b) para fundamentar essa discussão está ligado ao fato de o autor tratar justamente acerca do sujeito pobre, sobretudo preto e periférico, que depende exclusivamente do trabalho para sustentar suas famílias. Assim pensando, esta é a base para poder responder à questão de como é possível ficar isolado nesse contexto social e pandêmico, dependendo dos frutos da oferta de serviços, em geral não-essenciais, como é caso dos trabalhadores informais. Tais trabalhadores oferecem seus serviços atuando como entregadores, domésticas, pedreiros e etc. E por fim, esses são justamente os sujeitos tidos por descartáveis aptos a serem vítimas da dinâmica necropolítica. (MBEMBE, 2016) na qual se estrutura nosso país.

A trajetória histórica, política e social do cidadão no Brasil está entrelaçada com as relações de raça e as questões do racismo e da colonização, firmando desigualdades e segregações com evidente fruto nas bases escravagistas do país. O termo "subcidadania" cunhado por Souza (2018b) apresenta-se como eixo para análise das desigualdades e exclusões sociorraciais, sob a égide do racismo estruturalmente ambiental, tendo em vista a contraposição do real e do previsto pelo Sistema de Garantia dos Direitos da Pessoa Humana, expressos e garantidos de forma mandatória

beneficiários do programa e seus familiares (BRASIL, 2017) conforme estabelecido pelos documentos oficiais do programa." (GAIA; CANDIDO; BARBOSA JÚNIOR, 2019, p.115).

${ }^{5} \mathrm{Na}$ medida em que continua realizando suas atividades. É oportuno ressaltar que o programa realizou visitas normalmente até a data de 03/04. A partir daí, parte das visitas foi flexibilizada e é realizada por meio de telefone ou aplicativos de vídeo chamada, entretanto, uma parte da equipe continua atendendo a uma maioria das famílias, aquelas que não possuem acesso à internet ou telefone, mesmo com a recomendação de isolamento social, pois estes não têm outro meio de comunicação e o pagamento das atividades do PCF, por meio do Ministério da Cidadania, é realizado de acordo com dois fatores: equipe e meta de visita, conforme estabelecido pela Portaria n. 2.496/2018. (BRASIL, 2018; GAIA; CANDIDO; BARBOSA JÚNIOR, 2019). 
pela Constituição Federal de 1988. (BRASIL, 1988). Pensando nisso, e na tentativa de compreender o Brasil e sua história de forma inovadora, mostrando como a escravidão está presente sobre novas formas no cotidiano brasileiro hoje, nas formas de exploração tanto simbólicas como morais, é que o sociólogo Jessé Souza (2018b) trabalhou a sua obra "Subcidadania Brasileira: Para entender o Brasil além do jeitinho brasileiro" que mostra como e porque a exploração nesse país funciona de forma moral, simbólica e enraizada na escravidão. Na obra citada, Souza (2018b) destaca que a escravidão é a raiz dos grandes problemas do Brasil de hoje e argumenta também que esses problemas advêm da não inclusão da classe que ele concebe como subcidadão, entendendo que a exploração desses sujeitos, os subcidadãos, não tem cunho apenas econômico, mas, também moral, posto que para tal exploração ter funcionalidade é preciso investir em uma humilhação cotidiana e retirar dessas pessoas a autoconfiança e a capacidade de reação. (SOUZA, 2003; 2018b).

Souza (2018b) aponta para o auto-engano da classe média brasileira identificado no discurso de meritocracia, o qual é frequentemente usado como argumento contra a falta de inclusão e para justificar as desigualdades. De acordo com o autor (Ibid.), esta colocação não se sustenta devido ao papel da socialização familiar em cada classe social e ao fato de que as classes esquecidas não puderam desenvolver ações afirmativas. Souza (2018b) complementa ainda que apesar da lógica meritocrática entender que a desigualdade é fruto de um problema educacional, na verdade, explica ele, esta é uma questão que se inicia já na barriga da mãe, posto que os frutos de ventres pretos e pobres carregam no sangue um estigma do "perdedor" aos olhos da sociedade brasileira mais abrangente. (SOUZA, 2018a).

Gomes (2017) enfatiza como na escola, essas crianças, sobretudo negras, precisam lidar com as expectativas negativas de docentes que os enxergam apenas como alguém "sem futuro", indisciplinado e incorrigível. Souza (2018a) e Gomes (2017) refletem sobre o processo de civilização colonial sobre o qual a classe subcidadã é obrigada a passar para ser reconhecida socialmente e conseguir desenvolver perspectivas positivas para si mesmo. Trata-se, de acordo com Souza (2018a), de um movimento que demanda pela incorporação de conhecimentos legitimados pela elite acadêmica branca e colonizada através das universidades, instituições estas que na história do Brasil sempre atuaram como mecanismo de reprodução dessas mesmas elites sociais e econômicas.

Souza (2003; 2018b) explica que a classe do subcidadão é composta pelo material econômico e pela distinção social (a marginalização), tratando-se, por fim, de um produto da ação das elites, isto é, dos grandes proprietários, e, por outro lado, da classe média. As elites produzem essa classe a partir do ódio que sentem pelo pobre no Brasil, o qual se explica pelo ódio ao escravizado no período imperial, sendo o escravismo, portanto, um processo contínuo em nosso país. (SOUZA, 2018a). Isso, evidentemente, também inclui o racismo em nossa estrutura social. (ALMEIDA, 2018).

Em "A ralé brasileira: quem é e como vive", Souza (2018a) diz que este subcidadão é sinônimo do significado popular atribuído ao termo "ralé", reforçando que esses são 
aqueles que morrem em massa através de uma política informal de matar pobres realizada pelo aparato policial, o qual atua sobre os aplausos da classe média. Cria-se, então, uma hierarquia de valores $^{6}$ que diferencia cada ser humano por classe, tornando fácil agora compreender a naturalização do abissal quadro de desigualdades existentes no país. (SOUZA, 2005). Essas desigualdades, as quais definem quem estuda ou não, como quem vive ou quem morre, aponta Souza (SOUZA, 2003; 2018b), não se resolvem, como costuma crer a classe média e alguns pesquisadores ${ }^{7}$, apenas através do desenvolvimento econômico. Para incluir a classe subcidadã de forma eficiente, pois, segundo SOUZA (2018b) é preciso resgatar esses sujeitos de uma maneira que não seja automatizada.

Conforme expresso por Pierre Bourdieu (1983, p.82) “às diferentes posições que os grupos ocupam no espaço social correspondem a estilos de vida, sistemas de diferenciação que são a retradução simbólica de diferenças objetivamente inscritas nas condições de existência." Assim pensando, ao analisar a construção social da desigualdade, Souza (2003) entende o habitus ${ }^{8}$ como o responsável pela manutenção das classes precarizadas, atuando de forma a garantir que as classes vulneráveis continuem paradoxalmente vulneráveis. Segundo Setton (2002, p.65), o conceito de habitus "quer recuperar a noção ativa dos sujeitos como produtos da história de todo campo social e de experiências acumuladas no curso de uma trajetória individual", a qual é constituída por condição da cultura de massa, isto é, da "ralé" ${ }^{\text {, }}$, entre outros aspectos.

Para Jessé Souza (2018b), o resgate da classe dos subcidadãos só é possível compreendendo a questão das desigualdades sociais e refletindo o Brasil a partir dos problemas brasileiros de fato, ou seja, pensar o Brasil para e através do Brasil e suas problemáticas. E, de acordo com ele (2005), o fenômeno da desigualdade no âmbito geral no Brasil não pode se segregar da questão do racismo, assim como não é possível defender um trabalho científico que isole a variável racial das causas da desigualdade ${ }^{10}$. Souza (2005) explica que o quadro de marginalização social do negro se constitui através da redefinição moderna de conceituação desse sujeito, o que o coloca na condição de imprestável para qualquer atividade relevante e de prestígio dentro da sociedade. No entender do autor, a imprecisão das discussões acadêmicas acerca dos aspectos de classe e raça sobre o fenômeno da desigualdade no Brasil deriva, muitas das vezes, de motivações políticas fiéis à perspectiva que atribui a vítima (o negro) a culpa pela sua marginalização e condições desiguais. Todavia esse tipo de colocação não tem fundamento na linha de raciocínio construída por Souza (2005, p.66; 2018b, p.233, grifos do autor) que defende que "é precisamente o

\footnotetext{
${ }^{6}$ Hierarquia constituída nos laços eugenistas da formação do país, calculada pelo racismo em sua forma mais pura. (SOUZA, 2005).

${ }^{7}$ Pesquisadores que, em geral, têm origem nessas elites.

${ }^{8}$ Auxiliando a compreensão do referido conceito exposto, Setton (2002, p.61) conceitua habitus "como um instrumento conceptual que (...) auxilia pensar a relação, a mediação entre os condicionamentos sociais exteriores e a subjetividade dos sujeitos".

${ }^{9}$ SOUZA (2018a).

${ }^{10}$ No mesmo sentido, Domingues (2019) aborda a necessidade de um olhar para o impacto do racismo nas desigualdades do país a fim de que se garanta pleno regime democrático.
} 
abandono secular do negro (...) à própria sorte, a "causa" óbvia de sua inadaptação. Foi este abandono que criou condições perversas de eternização de um 'habitus precário', que constrange esses grupos à uma vida (...) à margem da sociedade incluída."

É nesses termos que Jessé Souza (2018b) mostra que a escravidão está viva e perpetuada atualmente através da exploração econômica, simbólica e moral da qual sofre a classe subcidadã. A ordem competitiva não é neutra e se hierarquiza por bases escravocratas, subjugando negros à marginalização social da classe subcidadã. (SOUZA, 2018b). Ainda,

Um outro ponto de imprecisão que no fundo duplica a ambiguidade em relação à opção de cor/habitus é a menção a coisas como "mundo branco" e "mundo negro", como se fossem, ambos realidades essenciais e independentes, e como se a hierarquia valorativa que articulasse essa disjuntiva não fosse, na realidade, uma única e subordinasse tanto "brancos" quanto "negros". Nesse ponto, [...] poderíamos refrasear a questão que formulamos e nos perguntar, afinal, o que está por trás das cores, especialmente da cor preta, que a faz menos visível, e que se manifesta por trás da cor? (SOUZA, 2018, p.232, grifos do autor).

Questões como essas não só evidenciam, como tornam inquestionáveis o legado de desigualdades raciais deixados pelos séculos de escravidão no país, o que por fim culmina no contexto político atual marcado, entre outros aspectos, pelas discussões sócio-políticas e demais consequências das últimas eleições presidenciais, em 2018. $\mathrm{Na}$ análise de Domingues (2019), ao problematizar os resultados finais do segundo turno, é possível observar que tais divisões raciais entraram em evidência no processo eleitoral, posto que o então presidente eleito, conhecido por falas polêmicas e abertamente racistas, teve forte apoio da elite citada por Souza (2018a; 2018b), a qual produz, explora, culpabiliza e odeia abertamente o subcidadão brasileiro, tal como o presidente em questão (SILVA, 2019). Em campanha, Bolsonaro falava para esse público específico, do qual o mesmo faz parte (GAIA et al., 2019) reafirmando as demandas da elite citadas por Souza (2018a; 2018b), ao fazer promessas como a da extinção de uma suposta política de "coitadismo" atribuída tanto ao negro, como a mulher, à população LGBTQI+ e nordestinos. (DOMINGUES, 2019). As posturas do presidente eleito em 2018 e analisadas por Domingues (2019) deixam nítido a total despreocupação do mesmo para com população negra, o que é somado também ao ódio e racismo anti-negro usualmente justificados pelo discurso meritocrata do mesmo. 


\section{O CONTEXTO POLÍTICO DO BRAZIL ${ }^{11}$, UM PAÍS OCIDENTALIZADO}

O julgamento de que idosos, mulheres e crianças são inferiores, e, portanto, também uma minoria social, é uma construção inerente ao berço civilizatório que orienta a cultura ocidental e o que nela se produz. (DIOP, 2014). Para iniciar esta seção é preciso compreender que o Brasil é um país, enquanto que o Brazil é outro, sendo Brazil a face ocidentalizada que reproduz essas percepções capacitativas, fruto de um histórico eugenista e despreocupado com a população melaninada ${ }^{12}$ que habita este país. (GAIA et al., 2019). Os Brasis, em seu hibridismo, interseccionam culturas múltiplas ainda que em nossos modos culturais sobressaiam posicionamentos de orientação ocidental. Afinal, vivemos numa ex-colônia formada na constante busca de se auto-ocidentalizar. (BOLSANELLO, 1996). É tanto por isso que, embora gere discussão, não se apresenta como uma grande surpresa que representações políticas desdenham da pandemia com o pretexto de que só atingirá de maneira letal aos mais velhos.

As posições assumidas pelas representações governamentais brasileiras têm se contrariado, na medida que enquanto o presidente da República banaliza a pandemia como uma simples "gripezinha", o Ministério da Saúde (durante a gestão de Luiz Henrique Mandetta) e os governadores dos estados tem buscado seguir as orientações da Organização Mundial de Saúde (OMS). (WERNECK, 2020) ${ }^{13}$. Essa divisão também é visível entre a população que, em parte, insiste em contrariar os comandos médicos internacionais e parece não compreender o sentido de uma pandemia. ( /bid., 2020). Os posicionamentos avessos são preocupantes não só pela necessidade da colaboração de todos para o enfrentamento desse problema, mas por simbolizarem um movimento que demonstra sintomas de uma patologia social. Isso porque as ações dos grupos que acompanham fielmente as falas do presidente Bolsonaro possuem teor egoísta e elitista, típicos de quem tem dificuldades em viver em sociedade, e um caráter negacionista quanto aos laudos científicos. Esta situação se reflete em pedidos, feitos em carreatas com os melhores carros do mercado, que exigem a volta da classe subcidadã ao trabalho através do slogan "O Brasil não pode parar" (/bid., 2020), ou através da definição de "comunista" a toda e qualquer pessoa que não esteja de acordo com as colocações e teorias pregadas nesses recentes protestos.

\footnotetext{
${ }^{11}$ A relação Brazil versus Brasil vem da canção “Querelas do Brasil”, interpretada por Elis Regina e escrita por Blanc e Tapajós (1978). A música é feita no contexto das críticas à ditadura civil militar iniciada em 1964 no país. Os artistas apontam para os diferentes Brasis existentes, apresentando dois lados muito distintos entre si. Entendemos que Brasil se trata das massas enquanto o Brazil da oligarquia que o sustenta. (GAIA et al., 2019). Os autores da canção evidenciam o processo de necropolítica acima denunciado quando diz que o "Brazil ta matando o Brasil" e também aponta para a distância entre ambos ao colocar "O Brazil nunca foi ao Brasil."

${ }^{12}$ Toda a classe de pessoas classificadas/lidas socialmente como não-brancos. Pela lógica eugenista, a população melaninada, aquele que acarreta maior grau de melanina na pele é tipificada pelo homem branco de acordo com quanto mais escuro forem.

${ }^{13}$ Porém, os conflitos entre representantes políticos têm dificultado este processo para com o público. O ápice dessa discussão foi a saída de Luiz Henrique Mandetta do Ministério da Saúde. (TV FOLHA, 2020).
} 
(CARNEIRO, 2020). Tais atitudes, supostamente preocupadas com a economia brasileira, são efeitos diretos que exemplificam o chamado bolsonarismo. (SILVA, 2019). A partir do trabalho de Silva (2019) podemos compreender elementos da ideologia bolsonarista, movimento que sintetiza perfeitamente o ódio dirigido ao subcidadão pela elite, sentimento conforme instruiu Souza (2018a).

O estudo de Silva (2019) explica que o contexto sócio histórico e político do Brasil é um espaço fértil para a consolidação do bolsonarismo e suas ideologias. A linha de raciocínio dos adeptos a esse movimento permitiu que chegassem à definição de que uma pandemia possa ser apenas uma "gripezinha". Um ponto forte desse bolsonarismo que colabora para as discussões de seus seguidores quanto a pandemia é o anticientificismo, desde as fakes news, o governo Bolsonaro conspira contra a ciência, questionando grandes instituições de pesquisa. (SENA JúNIOR, 2019). O negacionismo pode ser visto na cultura brasileira através de aspectos como, por exemplo, a ideologia do mito da democracia racial (NASCIMENTO, 2016) e a denegação, no sentido freudiano, de tudo o que é associado ao negro. (GONZALES, 1988). Trata-se de uma ideologia! (SENA JÚNIOR, 2019). Da mesma forma que o mito da democracia racial é uma ideologia construída por racistas em seu processo de negação. (SANTOS, 2015). Sena Júnior (2019) mostra ao longo do texto esse histórico anticientificista do governo Bolsonaro, inclusive pontuando a incompreensão do governo acerca do funcionamento da ciência e da importância das pesquisas nas áreas das humanidades. Também ao longo da história, coloca o autor, o anticientificismo gerou consequências negativas, ele dá o exemplo do holocausto judeu e da ideia de que o golpe militar de 1964 no Brasil é uma invenção. Com isso, concluí ele, é válido lembrar que toda história é uma revisão.

Mais do que um negacionismo à ciência, o bolsonarismo também retrata e representa o racismo à brasileira. (GAIA et al., 2019). Mas, de acordo com Gaia et al., (2019), é justamente esse o Brazil que deu certo, pois está de acordo com o projeto de nação ${ }^{14}$ estabelecido para esta eterna colônia de exploração. Nesses termos, a problemática racial do bolsonarismo em relação à pandemia põe sobre questão quem deve ou não morrer, reafirmando quem pode ou não ser eliminado nesse contexto de mortes. Tratase apenas da continuação do processo de necropolítica (MBEMBE, 2016), que está vigente desde as primeiras tentativas de democratização da república.

Portanto, não há motivo para se surpreender por essas reações políticas literalmente genocidas, posto o fato de que este é um país racista em que o atual presidente representa o pensamento da elite, do Brazil ocidentalizado, que odeia a subcidadania, odeia o negro/escravizado que vê nela (SOUZA, 2018a) e inferioriza não brancos, mulheres, idosos e crianças. (DIOP, 2014). As ações políticas presidenciais insistem que a população aceite a ideia de um sofrimento inevitável, demonstrando um descaso das representações do estado para com a seriedade dos dados estatísticos sobre a doença que gerou a então pandemia. (PLATERO; GOMES, 2020; WERNECK, 2020). O efeito disso sobre a população é o risco de uma falsa sensação de tranquilidade e seguridade de sua saúde. (Ibid., 2020; Ibid., 2020). Tais propostas

\footnotetext{
${ }^{14}$ BOLSANELLO (1996).
} 
incabíveis se orientam sobre a ética protestante e o espírito capitalista weberiano, a qual observamos prevalecer sobre a discussão acerca da COVID-19 no Brasil.

O ponto em questão é que os maiores prejudicados do slogan: "O Brasil não pode parar" são os trabalhadores classificados na subcidadania de Souza (2018b). Expostos ao vírus, sem acesso a um atendimento médico de qualidade, artigos de proteção e prevenção como água, sabão e álcool em gel e/ou, muitas das vezes, distantes das informações embasadas em evidências científicas, a ida desses sujeitos ao trabalho dá continuidade a um dos poucos processos que não irão parar com a pandemia: o genocídio e a necropolítica que os atingem. Ficam então as indagações: quem pode morrer e quais os critérios para tal seção? É sabido que os sujeitos matáveis no Brasil tem cor e habitam as periferias, esses sujeitos não possuem a mesma "proteção da cor da pele", como ocorre com os sujeitos brancos. (SIMAS, 2017). Agora, a condição dessa classe subcidadã nos núcleos de favela entra em contradição com as recomendações da OMS para enfrentar a pandemia.

Em meio a isso tudo, onde está a voz do favelado nessas discussões? O que esses sujeitos pensam e argumentam sobre esse assunto? A realidade é que aqueles que vivem em vulnerabilidade acabam se preocupando muito mais com a sobrevivência, com aquilo que há de imediato para sua subsistência do que com qualquer outra questão. (PADOIN; VIRGOLIN, 2010). Essa prioridade não é em vão porque estar em vulnerabilidade significa ser incapaz de enfrentar riscos e ser próximo a um bem estar social deficiente. (Ibid., 2010). Dentro disso, Padoin e Virgolin (2010) trabalham a ideia de que é preciso empoderar politicamente aqueles em vulnerabilidade para superar essa complexa realidade, tão persistente em nosso país. Isso significa que, para os autores (Ibid.), na medida em que o cerne mais duro da pobreza é o não acesso à uma autonomia emancipatória no seu sentido político, a subcidadania brasileira deve ter pensamento ativo e assumir participação política de maneira a alcançar sua autonomia individual e coletiva e reafirmar-se enquanto sujeito. Essa ideia é verdadeira, mas evidentemente, ilusória: dificilmente aqueles que mal comem terão disposição para discussões políticas e esta realidade, desde o período escravocrata, é uma velha condição estratégica de manutenção das classes dominantes, posto que o ocidente subjuga pela violência, e a violência pode ser tanto física, psíquica, como pode ser as duas, como é o caso da fome. Por essas e outras, Carolina Maria de Jesus (1960) dizia que o Brasil devia ser governado por quem já passou fome. Esse distanciamento da classe subcidadã dos debates políticos, entretanto, não significa que nenhum deles possa entoar voz ativa sobre suas demandas, como veremos a seguir.

\section{O ISOLAMENTO SOCIAL DOS SOCIALMENTE INVISÍVEIS: UM CENÁRIO DE MÚLTIPLAS DESIGUALDADES}

De acordo com Santos (2020), as favelas mundo afora convivem com a escassez de água e eletricidade, a falta ou precariedade de infraestrutura e saneamento básico e 
sem acesso, ou com dificuldades de acessar, serviços públicos básicos. Isso significa que estão desligados das condições do meio urbano que pressupõe o direito à cidade. (SANTOS, 2020). Somado a isso, também faz parte do cotidiano periférico a aglomeração de pessoas em pequenas residências. Vale ressaltar que essas questões são anteriores a pandemia e já estão naturalizadas, mas no contexto da necessidade de isolamento social, se agravam significativamente. Posto isso, entendemos que as favelas no Brasil sofrem uma marginalização que se enquadra no conceito de racismo ambiental, termo que surge na "dinâmica de segregação sócioespacial, onde os maiores incidentes de danos ambientais são condicionados às populações de baixa renda, étnica segregada e grupos sociais marginalizados." (SILVA, 2017, p.2). Segundo Silva (2017), o racismo ambiental é resultado da visão capitalista associada a ordem socioeconômica constituída através do racismo e, inevitavelmente, desterritorializa sujeitos sem poder aquisitivo. Ainda, ressalta o autor, através da propagação midiática que (re)produz estigmas racistas que conectam a ideia de pobre ao negro no imaginário social fica nítido que as vítimas do racismo ambiental são racializadas.

Assim, é fácil compreender a dinâmica do racismo ambiental ao observarmos que é a classe subcidadã quem habita essas regiões. (SOUZA, 2018a). Toda precarização encontrada nesses espaços são frutos diretos de uma priorização dos centros, junto a uma inferiorização das periferias. Dentro disso, talvez não seja exagero dizer que o ódio atribuído ao escravo foi herdado pelo subcidadão ( Ibid., 2018a), assim como os cuidados voltados para as senzalas reverberam no trato dos governos para com as periferias. Afinal, estamos falando do quarto de despejo, conforme bem disse a escritora Carolina Maria de Jesus (1960).

Ao que parece, quem tem se preocupado com a contabilização dos dados recorrentes do coronavírus nas comunidades periféricas são as próprias organizações de favelas. A organização Voz das Comunidades no Rio de Janeiro, onde mortos em dez comunidades somam 14 vítimas, e a União de Moradores de Paraisópolis em São Paulo tem contabilizado os dados de óbitos, confirmados e recuperados nessas periferias, tal como tem sido exemplos de solidariedade e trabalho conjunto. Trata-se de um grupo, ignorado pelo Estado brasileiro quando fora dos períodos eleitorais e do contexto dos interesses necropolíticos, e que, por consequência, busca sanar a falta do Estado através de ações conjuntas, exemplos de governabilidade e de organizações sociais eficientes. Também cabe destacar que o tráfico tem atuado nesse sentido, impondo o isolamento social, ainda que de maneira autoritária, assumindo a gravidade da situação, como ocorreu na Cidade de Deus, na zona oeste do Rio de Janeiro, onde já se contabiliza 07 confirmados e uma morte. (VOZ DAS COMUNIDADES, 2020; ISTO É, 2020). Por outro lado, os espaços periféricos da capital carioca também sofrem com imposições contrárias postas pelos grupos de milícia, que seguem a lógica bolsonarista acima abordada de que o país não pode parar. Assim, milicianos tem obrigado reabertura dos comércios, para dar continuidade a cobrança das taxas exigidas por eles à população. Nesse ponto, vale a ressalva, aqui não existe o interesse de julgar certa ou errada as atitudes assumidas pelo tráfico ou pela milícia, ambas organizações ilícitas, mas cabe apontar que nesse contexto fica nítido os 


\section{Edição Especial COVID-19}

interesses e as preocupações de cada grupo social, comumente em guerra, junto ao Estado, nas periferias. Também esse quadro por si só ajuda a explicar a complexa dinâmica periférica na qual se encontra essa população, quadro que vai muito além das problemáticas estruturais.

Quilômetros de distância, em outro contexto periférico, durante as visitas sociais nas periferias de Ribeirão Preto/SP, possíveis devido ao trabalho realizado pelo Programa Criança Feliz (PCF), observou-se as justificativas vindas diretamente desta população, as quais explicam as dificuldades em obedecer às recomendações de isolamento social. Em geral, os diálogos que incentivaram a produção desse artigo dizem respeito a três (03) principais empecilhos: a questão do espaço, um aspecto que pode ser pensado nos mais diversos contextos periféricos; as condições de trabalho e renda, também passível de generalidade, e a credibilidade das informações científicas versus o posicionamento do presidente em relação à doença, apesar deste último não contemplar todas as famílias.

As famílias atendidas pelo PCF alegam ter conhecimento acerca das problemáticas da COVID-19, mas, por se tratar de casas pequenas, muitas delas sendo apenas barracos feitos de madeira, enfrentam dificuldades para se manterem, exclusivamente, dentro de casa, sobretudo por conta das crianças que demandam por espaço para suas brincadeiras. A questão das limitações do espaço como obstáculo à prevenção fica nítida ao observar que as crianças brincam normalmente nas ruas dos bairros atendidos. Em geral, pode-se dizer que em Ribeirão Preto/SP, as favelas seguem suas rotinas e, até o presente momento, nada tem sido feito para conter os possíveis resultados negativos dessa situação ${ }^{15}$. Novamente, percebe-se que a vida das populações negras e periféricas não parece ter muito valor para as classes mais altas: contanto que distantes, não existe problema real.

O segundo ponto é que muitas dessas famílias ou sobrevivem exclusivamente dos benefícios socioassistenciais (quando beneficiárias) ou de trabalhos informais, em geral, profissões sem nenhuma garantia empregatícia. Um exemplo está na situação de uma família que retira seu sustento de faxinas rotineiras em diversas casas. Eles relataram que quase todos os patrões deixaram de pagar os pacotes pré-definidos, deixando então de receber um dinheiro com o qual contavam. Os patrões em questão afirmaram que apenas pagarão por faxinas feitas, deixando claro que era melhor 'torcer para não pegar o vírus, mas não faltar ao trabalho' (sic.). Fato é que sabemos que esse não é um caso isolado ${ }^{16}$. Trata-se do que Jessé Souza discorreu em "A ralé

\footnotetext{
${ }^{15}$ Embora o prefeito de Ribeiro Preto/SP, Duarte Nogueira (PSDB), tenha se posicionado favorável às orientações da OMS, decretando calamidade pública no município, ampliando, em 17 de abril de 2020, o período da quarentena através do Decreto no 91, o qual obriga que todo cidadão que utilizar espaço público utilize máscara facial. A desobediência do mesmo é passível de multa. Vale destacar que o Decreto em tela está em consonância com o artigo n. 268 do Código Penal vigente. (RIBEIRÃO PRETO, 2020; BRASIL, 1940).

${ }^{16}$ Inclusive fora feita uma carta assinada por filhos de empregadas domésticas denunciando essa e outras situações e suas problemáticas. Veja o manifesto intitulado "Pela vida de nossas mães". Disponível em: < https://www.brasildefato.com.br/2020/03/20/filhos-de-empregadas-domesticas-lancam-manifesto-pelodireito-a-quarentena-das-maes>. Acesso em: 23 abr. 2020.
} 
brasileira" (2018a), de que quando os sujeitos não tem acesso à uma escolarização de qualidade (fato comumente presente na realidade do ensino formal da população periférica) e/ou aos altos graus de escolarização, vende no mercado de trabalho sua energia muscular como um escravo. Ele inclusive cita as domésticas e/ou diaristas como o emprego feminino mais representativo da reprodução do escravo doméstico no Brasil. A empregada vende seu serviço a um preço mínimo, o tempo não gasto com os serviços braçais ofertados pela diarista ou doméstica é então usado pela classe média para estudar, entre outras atividades que os permitam ganhar inúmeras vezes mais que o salário que é pago para a empregada doméstica. (SOUZA, 2018a). Essa dinâmica servil, tão calcada na escravidão, é posta por Souza (2018a) como uma opressão modernizada de classe.

Quando é dito que a subcidadania precisa trabalhar para sobreviver, aborda-se a falta imediata de necessidades essenciais como alimentação e higiene, ao passo que esses subcidadãos costumam se sustentar dependendo de seu ganho diário, isto é, conseguem receber por dia apenas o necessário para o amanhã, comem o que recebem no dia. Esse quadro é bem explicado pelo diário de Carolina Maria de Jesus (1960).

Por último, mas não menos importante, uma pequena parcela das famílias atendidas posiciona-se politicamente contrárias à proposta de isolamento social. A justificativa é que entendem ser preciso ouvir o presidente em quem votaram, dando crédito unicamente as colocações do mesmo. Quando questionado acerca do posicionamento do Ministério da Saúde (durante a gestão Luiz Henrique Mandetta), parte do governo responsável por tratar da pandemia e com maior conhecimento na área, foi respondido que seu voto foi para o presidente, e não para o ministro, posteriormente demitido. Por isso, ainda que o presidente não seja nenhum especialista em vírus, optaram por seguir suas vidas normalmente.

Outra problemática que merece ser ressaltada é a inexistência ou o expressivo distanciamento de equipamentos públicos (de Saúde, Educação e Assistência Social) próximos aos territórios periféricos observados e a dificuldade das famílias se locomoverem até tais equipamentos. Isso reforça a sensação de invisibilidade e exclusão social e desenha um retrato fiel ao conceito de racismo ambiental praticado pelo Estado brasileiro contra esses moradores.

\section{CONSIDERAÇÕES FINAIS}

Tudo o que foi posto aqui acaba por se refletir na fala do ex-ministro da saúde Luiz Henrique Mandetta durante a despedida aos funcionários do Ministério da Saúde em 16 de abril de 2020, quando foi demitido pelo presidente da república. Ele diz:

[...] no dia que gente desse ministério [da saúde] me falou como que era o ônibus que ele vinha para cá, como que era o grau de proximidade das pessoas... e a gente falar em isolamento social como? O dia que a gente 


\section{Edição Especial COVID-19}

visita uma favela, vai falar em isolamento social como? O dia que a gente vê o transporte público e o SUS vai pagar a conta de séculos de negligência, de favela, de falta de saneamento básico, de falta de educação, de falta de cuidado com o povo mais humilde que é a grande massa trabalhadora desse país [...] (TV FOLHA, 2020).

A fala do ex-ministro é notória não apenas pelas observações trazidas explicitamente, mas pela informação implícita: a população mais abastada no Brasil desconhece a realidade daqueles que sofrem com as mazelas das desigualdades. Ainda assim, dependem deles e, despreocupados com suas condições, priorizam um potente massacre em razão da pandemia à reformulação dos seus estilos de vida. Esses discursos meritocratas são baseados na ideia de que o trabalho dignifica o homem, o que se confunde com a fé cristã (WEBER, 2007), permitindo a construção de religiosas hierarquias em um patamar de individualização não condizente com a proposta democrática. Por outro lado, está a classe subcidadã desprovida de direitos básicos (tanto humanos, como civis) e presa a uma cultura que naturaliza o medo do desemprego acima do medo da morte. Esses pesos e medidas são construções sociais que apenas fazem sentido no contexto do capitalismo global, tal como é hoje, e apenas pode incidir sobre a classe subcidadã de Souza (2018b). Isso porque no conforto de seus planos de saúde e acesso, tanto a informação, como a prevenção e a leitos particulares, as elites não parecem temer a morte. Além disso, habituados a um sistema que sempre os privilegia, muitos não se atentam para os informes acerca da falta de equipamentos médicos, mesmo nos hospitais particulares, isso por si só explica os diferentes sentidos de uma pandemia para as segregadas classes sociais no Brasil.

Posto isso, é preciso pontuar duas questões: a pós-Covid e as pesquisas científicas desse quadro como um todo. Fica aqui a reflexão acerca das possíveis consequências da pandemia no Brasil, no mundo e sobretudo nas favelas. Este é um cenário que também apavora, talvez tanto quanto a situação atual. O desconhecido naturalmente assusta os seres humanos, mas para aqueles que recorrentemente desconhecem o amanhã, o presente caos se atenua. Tanto por isso temos a ciência para auxiliar. Não se trata de uma solução concreta para os movimentos políticos, econômicos e sociais que possivelmente irão derivar do coronavírus, mas é sem dúvida o amparo mais confiável para todos os futuros dilemas. Nesse sentido, o Brasil vem perdendo há meses. Além do histórico negacionismo à ciência (SENA JúNIOR, 2019), alguns brasileiros, dentre eles o agora também ex-ministro da educação, Weintraub, desprestigiam muitas das universidades públicas e pesquisadores recorrentemente, além de propagarem a ideia de que a ala médica por si só será capaz de conter o problema. Esse engano não diz respeito apenas à desconsideração pelas outras áreas que trabalham na linha de frente contra o coronavírus, mas pela ignorância acerca de como a ala científica trabalha nas ocasiões de crises. Além de médicos e demais profissionais da saúde, biólogos especialistas na área dos vírus, bioquímicos, economistas, cientistas políticos, sociólogos, administradores, assistentes sociais, comunicadores, professores, profissionais da informática, por exemplo, tem papéis fundamentais para sobreviver ao momento em que vivemos, cada um à sua maneira. 
Por isso, concluímos defendendo as pesquisas científicas em todas as áreas acadêmicas, entendendo a importância na luta contra o coronavírus, sobretudo a área das ciências humanas, agora ainda mais castigada e que em termos de economia e políticas públicas são tão urgentes quanto a classe médica, que não pode governar essa crise sozinha. Afinal, jogar mais essa responsabilidade a estes profissionais seria tão covarde como culpar a classe subcidadã que não tem ido trabalhar pelo desamparo econômico resultante da suposta "gripezinha".

No mais, no restante do globo, o quadro demonstra-se muito diferente quanto ao tratamento desta complexa questão de saúde pública, o que se confirma com os números que vem abaixando nos outros continentes, em contrapartida as Américas. (WHO, 2020). A 28 de abril de 2020, temos 2.957.350 casos confirmados e 207.961 mortes em todo o mundo, de acordo com site das Organização Mundial da Saúde (2020) destinado a atualizar acerca da pandemia. Dentro esses dados, desde 17 de março, os continentes americanos lideram o número de casos, superando a Europa, onde a disseminação do vírus ganhou força. Os dados expostos pelas Organização Mundial da Saúde (2020) também mostram que o continente africano e o oeste do Pacífico mantêm os menores índices.

O presente artigo se fez necessário em decorrência da relevância da discussão acerca dos efeitos sociais do coronavírus no país seguir um modelo histórico de pesquisas que desconsideram as questões de classe e raça. Não é admissível a um pesquisador das ciências humanas ou sociais descartar esses pontos e assumir jargões como o de que o vírus não vê cor ou classe. O vírus pode não ver a quem afeta, mas nossas pesquisas devem ver. Os discursos que temos observado caminham na direção de pesquisas potencialmente insuficientes para a complexidade das relações raciais no Brasil. Vê-se que estas seguem a tradição de privilegiar debates rasos e superficiais, os quais geralmente restringem-se a estudos voltados ao capitalismo que não têm capacidade de enxergar a periferia como um subproduto do capital e para análises marxistas que não problematizam a escravidão ou a deficiência de reparações históricas eficientes. Nossa crítica a essa falha na problematização da questão de raça e/ou classe no contexto da pandemia não se justifica pelo fato de que o problema é recente e ainda desconhecido para muitos, pois estas questões são os grandes pilares das desigualdades construídas no país, as quais, como bem sabem os campos das ciências econômicas e políticas públicas, tendem a agravar com esta situação. Nesse sentido, argumentamos que o marxismo não serve para nenhuma perspectiva racializada (DOVE, 1995) e que o Brasil precisa ser olhado pelo viés da raça por sua dinâmica sócio-histórica, política e cultural e fenotípica.

Nesses termos, entendemos que enquanto o Estado não assumir seu papel com a devida qualidade nos espaços de periferias onde reside a subcidadania, isto é, enquanto prevalecer a estrutura sócio-política que alicerça nosso país, o isolamento social nas favelas não será possível, mesmo que com o apoio popular. Mas com posições verdadeiramente preocupadas com as calamidades que a pandemia já vem causando, é possível conter esses problemas. Tanto por isso, agora não somente importa como são urgentes estudos nas ciências humanas e sociais que possam 
assistir e desenvolver políticas de acordo com as condições palpáveis e em diálogo com os pesquisadores da saúde.

\section{REFERÊNCIAS}

ALMEIDA, S. L. O que é racismo estrutural? Belo Horizonte: Letramento, 2018. BLANC, A.; TAPAJÓS, M. Querelas do Brasil. In: REGINA, Elis. Transversal do Tempo. Rio de Janeiro: Philips/Polygram, 1978.

BOLSANELLO, M. A. Darwinismo social, eugenia e racismo científico: sua repercussão na sociedade e na educação brasileiras. Educar, Editora da UFPR, Curitiba, n.12, p.153- 165, 1996.

BOURDIEU, Pierre. Gostos de classe e estilos de vida. In: ORTIZ, Renato (org.).

Bourdieu - Sociologia. São Paulo: Ática. Coleção Grandes Cientistas Sociais, v.39, p.82-121, 1983.

BRASIL. Código Penal. Decreto-Lei no 2.848, de 7 de dezembro de 1940.

BRASIL. Constituição da República Federativa do Brasil. Brasília, DF: Senado Federal: Centro Gráfico, 1988. 292 p.

BRASIL. Portaria n. 2.496, de 17 de setembro de 2018. Diário Oficial da União, Brasília, 18 set. 2018.

CARNEIRO, M. Carreata contra isolamento foi de poucos, com BMW e Land

Rover, diz Caiado. Folha de São Paulo. São Paulo, 30 mar. 2020. Disponível em: $<$ https://www1.folha.uol.com.br/colunas/painel/2020/03/carreata-contra-isolamento-foi-de-poucos-combmw-e-land-rover-diz-caiado.shtml>. Acesso em: 27 abr. 2020.

DIOP, Cheikh Anta. A Unidade Cultural da África Negra: esferas do patriarcado e do matriarcado na antiguidade clássica. Angola: Pedago, 2014.

DOMINGUES, Petrônio. Democracia e autoritarismo: Entre o racismo e o antirracismo. In: ABRANCHES, Sérgio; Et. al. Democracia em risco?: 22 ensaios sobre o Brasil hoje. São Paulo: Companhia das Letras, 2019. p.98-115.

DOVE, Nah. Uma Crítica Africano-Centrada à Lógica de Marx. Tradução: Wellington Agudá. Jornal Ocidental dos Estudos Negros, v.19, n.4, 1995.

GAIA, Ronan da Silva Parreira; CANDIDO, Thais Peterossi; BARBOSA JÚNIOR, Washington de Bessa. O Programa Criança Feliz e suas contribuições para o Desenvolvimento da Criança na Primeira Infância: Apontamentos sobre o caso de Ribeirão Preto/SP. Revista Sociais e Humanas, Santa Maria, v.32, n.2, p.112-125, 2019. Disponível em: <https://periodicos.ufsm.br/sociaisehumanas/article/view/ 37746>. Acesso em: 15 abr. 2020. 
GAIA, Ronan da Silva Parreira et al. A nova política dos velhos tempos: reflexões sobre a construção de um projeto de nação. Áskesis, v.8, n.1, p.40-55, 2019. Disponível em: <http://www.revistaaskesis.ufscar.br/index.php/askesis/article/view/389>. Acesso em: 20 abr. 2020.

GOMES, Nilma Lino. O movimento negro educador. Saberes construídos nas lutas por emancipação. Petrópolis/RJ: Editora Vozes, 2017.

GONZALEZ, Lélia. A categoria político-cultural de amefricanidade. Tempo Brasileiro, Rio de Janeiro, n.92/93, p.69-82, jan./jun. 1988.

ISTO É. Corona Vírus: traficantes usam faixas para proibir aglomerações na cidade de Deus. Publicado em 13 abr. 2020. Disponível em: < https://istoe.com.br/coronavirustraficantes-usam-faixa-para-proibir-aglomeracoes-na-cidade-de-deus/>. Acesso em: 20 abr. 2020.

JESUS, Carolina Maria de. Quarto de despejo - diário de uma favelada. São Paulo: Francisco Alves, 1960.

MBEMBE, Achille. Necropolítica. Artes \& Ensaios, v.32, p.123-151, 2016.

NASCIMENTO, A. O Genocídio do Negro Brasileiro: processo de um racismo mascarado. 3. ed. São Paulo: Perspectivas, 2016.

OLIVEIRA, Caroline. Filhos de empregadas domésticas lançam manifesto pelo direito à quarentena das mães. BRASIL DE FATO. São Paulo, 20 mar. 2020. Disponível em: <https://www.brasildefato.com.br/2020/03/20/filhos-de-empregadas-domesticaslancam-manifesto-pelo-direito-a-quarentena-das-maes >. Acesso em: 21 abr. 2020.

PADOIN, I. G.; VIRGOLIN, I. W. C. A vulnerabilidade social como uma dificuldade a participação política. In: Seminário Interinstitucional de Ensino, Pesquisa e Extensão. Cruz-Alta: UNICRUZ, 2010.

PLATERO, K A S; GOMES, F. Números estatísticos e realidades: Uma proposta de reflexão sobre a pandemia de Covid-19 no Brasil. Dilemas: Revista de Estudos de Conflito e Controle Social, Rio de Janeiro, Ensaio de análise de conjuntura, p.1-8, 2020. Disponível em: <https://www.reflexpandemia.org/texto-5>. Acesso em: 17 abr. 2020.

RAMOS, Alberto Guerreiro. Introdução crítica a sociologia brasileira. Rio de Janeiro: Editora UFRJ, 1995. p.292.

RIBEIRÃO PRETO. Decreto n. 91, de 17 de abril de 2020. Dispõe, no âmbito do município de Ribeirão Preto, medidas de proteção à coletividade a serem adotadas para enfrentamento do estado de calamidade pública e de emergência de saúde pública decorrente do coronavírus - Covid19, e dá outras providências.

RODRIGUES, Rodrigo; BORGES, Beatriz; FIGUEIREDO, Patrícia. Morumbi tem mais casos de coronavírus e Brasilândia tem mais mortes; óbitos crescem $60 \%$ em uma semana em SP. G1 SP. São Paulo, 18 abr. 2020. Disponível em:

<https://g1.globo.com/sp/sao-paulo/noticia/2020/04/18/morumbi-tem-mais-casos-de-coronavirus-ebrasilandia-mais-mortes-obitos-crescem-60percent-em-uma-semana-em-sp.ghtml >. Acesso em: 21 abr. 2020. 
SANAR MED (Org.). Linha do tempo do Coronavírus no Brasil. 2020. Disponível em: <https://www.sanarmed.com/linha-do-tempo-do-coronavirus-no-brasil>. Acesso em: 20 abr. 2020.

SANTOS, Boaventura de Souza. A Cruel Pedagogia do Vírus. Coimbra: Almedina, 2020.

SANTOS, Hélio. [2002]. Entrevista ao Programa Roda Viva. In: TV Cultura. 2015. Disponível em: <https://www.youtube.com/watch?v=1e6HHctgWPk>. Acesso em: 29 de março de 2019.

SENA JÚNIOR, C. Obscurantismo e Anticientificismo no Brasil Bolsonarista: anotações sobre a investida protofacista contra a inteligência e a ciência no Brasil. Cadernos do GPOSSHE On-Line, v.3, n.1, p.21-49, 2019.

SETTON, M. G. J. A Teoria do Habitus em Pierre Bourdieu: uma leitura contemporânea. Revista Brasileira de Educação, Rio de Janeiro, n.20, p.60-70, 2002.

SILVA, E. F. Os direitos humanos no "bolsonarismo": "descriminalização de bandidos" e "punição de policiais". Conhecer: Debate entre o Público e o Privado, n.22, p.133-153, 2019.

SILVA, Vinícius Santos da. Favela: não somos marginais, fomos marginalizados.

Revista Eletrônica História, Natureza e Espaço, v.6, n.1, p.1-8, 2017.

SIMAS, Luiz Antonio. Liberdade Religiosa, Intolerância e Racismo. In: Canal Philos. YouTube, 11 abr. 2017. Disponível em: <https://www.youtube.com/watch?v=FRdOLYFFrLQ>. Acesso em: 14 mai. 2019.

SIMÕES, Nataly. Biólogo explica porque a população negra é a mais impactada pelo coronavírus no Brasil e nos EUA. ALMA PRETA. Publicado em 17 abr. 2020.

Disponível em: <https://www.almapreta.com/editorias/realidade/biologo-explica-porque-a-populacaonegra-e-a-mais-impactada-pelo-coronavirus-no-brasil-e-nos-eua >. Acesso em: 20 abr. 2020.

SOUZA, Jessé. A construção social da subcidadania: para uma sociologia política da modernidade periférica. Belo Horizonte: Editora da UFMG, 2003.

SOUZA, Jessé. A ralé brasileira: quem é e como vive. 3. ed. São Paulo:

Contracorrente, 2018a.

SOUZA, Jessé. Raça ou classe? Sobre a desigualdade brasileira. Lua Nova, São Paulo, n.65, p.43-69, 2005.

SOUZA, Jessé. Subcidadania Brasileira: para entender o país além do jeitinho brasileiro. Rio de Janeiro: LeYa, 2018b.

TV FOLHA. Os últimos minutos de Mandetta no Ministério da Saúde. In: YouTube. 17 de abril de 2020. Disponível em: <https://www.youtube.com/watch? $\underline{v}=890 u L W y 6$ XIM\&feature=youtu.be $>$. Acesso em: 22 abr. 2020.

VOZ DAS COMUNIDADES. Covid-19 nas Favelas. 2020. Disponível em: <https://covid.vozdascomunidades.com.br/>. Acesso em: 21 abr. 2020. 
WEBER, Max. A ética protestante e o “espírito" do capitalismo. São Paulo:

Editora Schwarcz Ltda., 2007.

WERNECK, Alexandre. Graça em tempos de desgraça? A jocosidade como operador da crítica na pandemia. Dilemas: Revista de Estudos de Conflito e Controle Social, Rio de Janeiro, Ensaio de análise de conjuntura, p.1-16, 2020. Disponível em:

<https://www.reflexpandemia.org/texto-2>. Acesso em: 17 abr. 2020.

WORLD HEALTH ORGANIZATION. [WHO]. Coronavirus Disease (COVID-19). 2020. Disponível em: <https://covid19.who.int/>. Acesso em: 28 abr. 2020. 